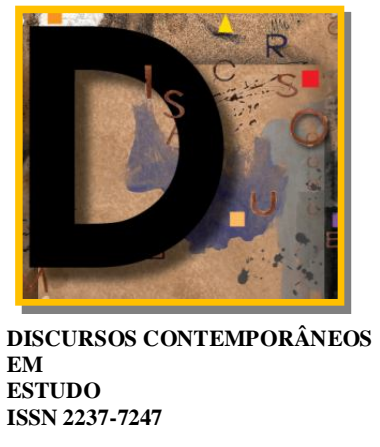

\title{
UM OLHAR DA ANÁLISE DE DISCURSO CRÍTICA SOBRE A GRAMÁTICA
}

Josenia Antunes Vieira $(\mathrm{UnB})^{1}$

O objeto deste artigo é examinar a gramática sob a ótica do discurso. Em particular, discute a gramática em sua relação com a Análise de Discurso Crítica (ADC). Para isso, examina a relação fundamental de dois modelos linguísticos contemporâneos - o modelo formalista e o modelo funcionalista. A perspectiva da ADC incorpora princípios da Gramática Sistêmico-Funcional em seu instrumental de análise e utiliza conceitos como o de gramaticalização e de desgramaticalização segundo a perspectiva da ADC.

Palavras-Chave: Análise de Discurso Crítica. Gramática.

The object of this paper is to examine the grammar from the viewpoint of the speech. In particular, it discusses the grammar in its relationship with Critical Discourse Analysis (CDA). To do so, examines the fundamental relationship of two contemporary linguistic models - the formal model and the functional model. The prospect of CDA incorporates principles of Systemic Functional Grammar in his instrumental analysis and uses concepts such as grammaticalization and desgramaticalization from the perspective of CDA.

Keywords: Critical Discourse Analysis. Grammar.

\footnotetext{
${ }^{1}$ Pós-Doutora em Análise de Discurso Crítica (CNPq, 2001) pela Universidade Clássica de Lisboa; professora e pesquisadora do Programa de Pós-Graduação em Linguística (PPGL) da Universidade Brasília (UnB). E-mail: josenia.unb@gmail.com.
} 


\section{Introdução}

O objeto deste artigo é examinar a gramática sob a ótica do discurso. Em particular, desejamos discutir a gramática em sua relação com a Análise de Discurso Crítica (ADC). Para isso, examinaremos a relação fundamental de dois modelos linguísticos contemporâneos - o modelo formalista e o modelo funcionalista. A perspectiva da ADC, por seus propósitos teóricos e analíticos, afasta-se do modelo formal para incorporar princípios da Gramática SistêmicoFuncional em seu instrumental de análise.

Conforme Halliday (1994), é possível justificar essa escolha por três razões: pela forma de interpretar textos, pelo modo de interpretar o sistema linguístico e pela interpretação dos elementos das estruturas da linguagem. Por essas razões, a Gramática Funcional é, no momento, a abordagem que dá conta de analisar a linguagem em uso, pois o modelo funcional não aspira à descrição de estruturas faladas por sujeitos ideais que operam um conjunto de regras, como nos modelos linguísticos de descrição formal, mas deseja, efetivamente, estudar eventos discursivos nos quais os falantes produzem textos falados ou escritos que permitem a identificação do contexto, da cultura e das práticas discursivas subjacentes ao discurso. No mesmo intuito,

pretendemos observar também as tendências da análise funcional, para analisar a gramática em sua forma mais natural do discurso: a interação discursiva realizada em um ato discursivo.

\section{O discurso e a gramática}

Sob a perspectiva do enfoque discursivo-funcionalista, na concepção de Hooper (1988), examinaremos a relação do discurso com a gramática. Os linguistas funcionais defendem que o discurso falado ou escrito, por sua natureza, é o âmbito apropriado para estudar as gramáticas das línguas do mundo, por não ser apenas o lugar em que a gramática está em uso, mas também a forma de linguagem de cuja fonte surge a gramática.

Com base nesse ponto de vista, podemos dizer que a gramática se origina, prioritariamente, dos padrões recorrentes do discurso, responsáveis por sua configuração. Essa maneira de abordar a gramática difere do que se poderia chamar de enfoque "autonomista", segundo o qual a gramática é constituída inteiramente independente dos usos comunicativos, sendo resultado, portanto, de características biológicas inatas e não de elementos do contorno sociocultural que orientam e ajudam o sujeito a definir empregos e papéis gramaticais, além de auxiliá-lo na percepção das ideologias construídas e perpassadas pela gramática.

A perspectiva discursivo-funcional da gramática, conforme Cumming e Ono (2000), fundase em dois princípios: um descritivo e outro objetivo. $\mathrm{O}$ primeiro questiona como o sujeito 
escolhe os recursos gramaticais diante da riqueza de possibilidades que dispõem as línguas para expressar o mesmo conteúdo; como agem os falantes para selecionar mecanismos discursivos na presença da extensa gama de alternativas gramaticais. Podemos nos perguntar, por exemplo, como os falantes elegem uma frase nominal ou um pronome em vez de outra alternativa linguística; ou como o sujeito escolhe entre duas ordens possíveis de sujeito e verbo (SV) em vez de verbo e sujeito (VS). O princípio descritivo indaga o motivo por que as línguas usam determinados recursos gramaticais e não outros.

O segundo princípio, o objetivo, é explicativo. Procura respostas para as estratégias e para o uso de determinados recursos gramaticais em eventos discursivos, como e de que forma os pronomes são utilizados, por exemplo. Sabemos que, mesmo existindo em muitas ou em todas as línguas, os pronomes realizam-se no exercício de certas funções e em certos tipos de formas, de acordo com padrões avaliativos do sujeito. Conforme a imagem construída sobre o interlocutor, julgamos os limites e os graus de intimidade com que devemos tratar o outro no discurso e nas interações face a face.

Para alcançar esse propósito, os linguistas da área da ADC, que trabalham com a gramática, propõem três classes gerais de explicações: as cognitivas - que consideram os recursos e os processos cognitivos utilizados pelos falantes para compreenderem e para produzirem os seus discursos -; as sociais e interativas - que enfocam a dinâmica das situações interacionais em momentos de produção e de consumo da linguagem e também as normas, os recursos e os objetivos sociais e culturais dos participantes do evento discursivo -; e, por último, as explicações de mudança gramatical, o fenômeno de gramaticalização e de desgramaticalização, cujas explicações se centram na relação entre as pressões discursivo-funcionais e a realização gramatical.

Como ilustração de casos em que ocorrem mudanças gramaticais, verificaremos, neste momento, exemplos de gramaticalização e de desgramaticalização em discursos produzidos por sujeitos residentes em Brasília. Examinaremos eventos discursivos, como: “A babá foi tomar de conta das crianças", no lugar de "A babá foi tomar conta das crianças"; "Preciso um emprego com urgência" por "Preciso de um emprego com urgência". No primeiro caso, com o acréscimo da preposição "de" ao verbo, ocorre o fortalecimento de um comportamento gramatical, uma gramaticalização. No segundo, com o apagamento da preposição "de", há o enfraquecimento de um traço gramatical, uma desgramaticalização. Ambos são casos típicos de mudanças gramaticais recorrentes em discursos variados que atestam a visibilidade das alterações gramaticais, provocadas pelo uso discursivo.

Além desses exemplos, podemos mencionar, entre outros, a desgramaticalização das conjunções coordenadas, principalmente das adversativas, das explicativas e das conclusivas. 
Nesse sentido, como pode ser visto no exemplo a seguir, elas são utilizadas como recursos enfáticos ou estilísticos e não mais como conjunção especificamente. Vejamos o exemplo seguinte: "As gramáticas, contudo, não permitem ao falante uma livre escolha das formas." Em tal circunstância, a conjunção abandona a sua função gramatical: a de ligar duas orações, para assumir papel claramente discursivo, com contornos estilísticos e até mesmo retóricos, não atuando mais como elo conjuntivo funcional.

Confrontada com os casos citados e com os exemplos a seguir: "Eu fiz isto pra tu" em vez de "Eu fiz isso para ti"; "É pra mim fazê o trabalho" por "É para eu fazer o trabalho", a ADC é incitada não apenas a descrever fatos gramaticais, mas, sobretudo, a explicitar que forças discursivas pressionam o sujeito de um discurso para realizar inversões, apagamentos, mudanças nos valores gramaticais. No primeiro exemplo, o pronome do caso sujeito - tu - passa a ser utilizado como pronome objeto e, no segundo caso, o pronome objeto - mim - passa a ser empregado como pronome sujeito, refletindo a prática social hegemônica de determinados sujeitos com reduzido letramento formal.

A respeito de discurso e de gramática, ainda cabe dizer que essas explicações não se excluem mutuamente, antes, interrelacionam-se de muitas maneiras. Os analistas do discurso defendem que o vasto repertório formal existente nas línguas do mundo é produzido devido a diferentes pressões funcionais que, em muitos casos, competem entre si, obrigando as comunidades de fala a eleger as formas linguísticas mais motivadas nos discursos que, muitas vezes, ao promoverem padrões de estruturas gerais e universais, convergem.

Na vertente da ADC, como propõe Fairclough (1992), antes da produção de cada discurso, ocorre uma luta de poder entre determinadas expressões e formas discursivas, prevalecendo a prática discursiva hegemônica dos eventos discursivos mais fortes. Ainda que, à luz da gramática normativa, determinados discursos sejam considerados errados, esses são os eleitos para serem produzidos pelos sujeitos do discurso. O que o desejo ratificar mais uma vez é que a prática social, aliada à luta de poder, elegerá para as escolhas na produção do discurso e, consequentemente, das formas gramaticais.

\section{Alguns aspectos relevantes da Gramática Funcional}

Em oposição ao enfoque dos linguistas formais (autonomistas), surgiu a escola Linguística Funcional americana em meados da década de 1970. A construção da Gramática Funcional como um movimento definido deve muito às abordagens sociais e comunicativas europeias, em especial a Firth, cuja abordagem foi ampliada por Halliday (como pode ser visto em Halliday (1967) e em outros trabalhos resenhados em 1994). Do mesmo modo, a Linguística 
Funcional está em débito com a corrente da Escola de Praga, chamada Perspectiva Funcional da Oração, legada por Firbas (1966), Danes (1974) e Mathesius (1975), entre outros. De acordo com esses enfoques, o meio social e a função comunicativa da linguagem e, acima de tudo, a gestão da informação no discurso são aspectos fundamentais para a compreensão da gramática.

Um outro grupo de linguistas americanos que também contribuiu com seus estudos nessa época foi o de Bolinger, o qual empreendeu larga série de estudos (BOLINGER, 1952; 1986; 1989) que demonstram a importância de se entender a linguagem em uso. Bolinger foi um dos primeiros a estudar as características especiais da língua falada, em particular, a entonação.

Os representantes legítimos do enfoque linguístico, que considerou o discurso como elemento essencial para estudar a linguagem, foram Pike (1954); Longacre (1972) e Grimes, (1975). De igual modo, Greenberg (1966) centrou a atenção nas propriedades universais das línguas humanas e, juntamente com ele, seus seguidores formularam leis de implicações universais. Essas novas observações requeriam explicações que apenas os enfoques discursivosfuncionais estavam aptos a oferecer.

Surgiram também, em meados de 1970, outros estudos afins, como a Psicolinguística, a Sociolinguística e a Linguística do Texto, que têm exercido, desde então, influência significativa no enfoque da Gramática Funcional. Outras influências relevantes exercidas sobre a abordagem funcionalista provêm da Antropologia e da Sociologia. Ademais, como já foi dito, os linguistas funcionalistas sustentam que a utilização da linguagem para a comunicação em situações naturais é um aspecto fundamental da organização das línguas. Consideram a gramática presente no discurso não apenas um objeto a ser descrito, mas, principalmente, uma fonte genuína de explicações para as ocorrências gramaticais.

\section{O papel da Gramática Funcional na Análise de Discurso Crítica}

Nas últimas décadas, o número de linguistas que defendem o estudo da linguagem em uso tem aumentado rapidamente; em proporção inversa, os defensores do enfoque autônomo tendem a diminuir. No contexto atual, o pesquisador, ao selecionar um determinado corpus para estudo, concentra-se em dados da realidade e não em dados idealizados. O investigador inclui hoje, na base de dados, a maior quantidade possível do contexto em que o discurso ocorre, contemplando não apenas o contexto linguístico, mas também o cultural e o extralinguístico, além dos aspectos sociais e físicos. Isso se deve ao fato de que, muitas vezes, apenas o contexto pode indicar e fornecer pistas sobre pressões funcionais relevantes, impossíveis de serem identificadas quando examinamos apenas os dados linguísticos. 
Nesse sentido, em relação aos dois modelos fundamentais da linguística contemporânea o formalista e o funcionalista -, mesmo com risco de incorrer em algum reducionismo, podemos dizer que ambos têm alcançado atenção especial nos estudos da linguagem. Nesses estudos, a concepção funcional tem se desenvolvido mais no momento atual.

Na concepção de Halliday (1994), a proposta funcional liga-se diretamente aos textos, às estruturas e ao sistema linguístico. A gramática, por essa razão, intitula-se funcional porque tenciona dar conta do uso da linguagem. Desse modo, esse modelo não pretende descrever as estruturas linguísticas utilizadas por falantes ideais, mas deseja estudar, principalmente, o discurso real e efetivo dos falantes no momento de produção de discursos escritos e falados.

Qualquer componente da Gramática Funcional é explicado em relação à sua função no sistema linguístico pleno. Assim, a Gramática Funcional resulta da construção funcional da própria língua, em que cada parte exerce determinada função ligada ao sistema linguístico como um todo. Nas palavras de Halliday (1994, p. xiii), todo o texto falado ou escrito se realiza em algum contexto de uso. Além disso, é o uso da linguagem que tem dado forma ao sistema. Ao longo do tempo, a linguagem tem evoluído para satisfazer as necessidades humanas e, por essa razão, o seu modo de organizar-se é funcional, ligando-se diretamente às necessidades dos usuários. Em consequência, qualquer manifestação discursiva deixa de ser arbitrária para ser claramente motivada. A característica preponderante da Gramática Funcional é, portanto, ser, essencialmente, uma gramática natural, no sentido de que todas os eventos discursivos podem ser explicados por referência ao modo como a linguagem é empregada.

A Gramática Sistêmico-Funcional defende que todos os usos linguísticos, por parte do adulto, são, em verdade, a expressão de três metafunções denominadas de função ideacional, função interpessoal e função textual. A primeira delas, a ideacional, traduz o mundo conceitual presente no discurso e também o modo como este é concebido, tanto no campo da lógica, como no da experiência. A segunda, a função interpessoal, regula as relações do sujeito do discurso com o outro e o seu próprio modo de agir em termos interacionais. A terceira, a função textual, diz respeito especificamente ao modo de organizar o texto, quer seja ele escrito, quer seja falado, com o propósito de torná-lo coeso e coerente e sobretudo significativo.

Essas três funções ocorrem simultaneamente em qualquer evento discursivo e apenas se separam para efeito de análise, pois elas estão permanentemente presentes nos textos. Mesmo assim, é possível examinar a predominância de uma ou de outra função em um texto. Em uma tese ou dissertação, certamente, o uso mais expressivo será o da função ideacional, considerando que o mundo conceitual terá prioridade. Do mesmo modo, a função interpessoal será proeminente em um diálogo. 
Outro acréscimo considerável que o modelo funcional traz é a proibição de o texto ser intuído fora de seu contexto de uso. Vale lembrar que os dois contextos considerados na visão funcional são o de cultura e o de situação. Quanto ao contexto de cultura, deve ser enfatizado que qualquer texto se enquadra em um gênero determinado culturalmente e que todo o sujeito, por estar imerso em uma dada cultura, consegue lê-lo e compreendê-lo de imediato. Desse modo, o sujeito do discurso é capaz de distinguir os gêneros legítimos daqueles que, por ventura, não pertençam à sua cultura.

No que concerne ao contexto de situação, encontraremos, na Gramática Funcional, a noção de registro ou variedade em conformidade com o uso. A noção de registro traz implícitas três variáveis, diretamente relacionadas às três macrofunções mencionadas anteriormente: a noção de campo, aquilo de que se fala, o tópico, diretamente relacionado à função ideacional; a noção de relações, ligada à função interpessoal; e a noção de modo, que remete à metafunção textual. Assim, texto, contexto de cultura e de situação relacionam-se intimamente na perspectiva da Gramática Funcional.

As três metafunções, entretanto, não se manifestam apenas pelas características contextuais, mas, também, pelo sistema léxico-gramatical, que é utilizado na produção de textos. Cada uma das macrofunções realiza-se explicitamente em um sistema concreto da gramática. Segundo Halliday (1994), uma gramática funcional baseia-se em significados, mas, por ser uma gramática, ela é uma interpretação das formas linguísticas.

Segundo essa visão funcional, as metafunções expressam-se do seguinte modo: a ideacional no sistema de transitividade, a interpessoal no sistema de modo e de modalidade e a textual no sistema de tema e de rema. O sistema de transitividade é basicamente um recurso gramatical para construir ações e atividades, representadas como configurações de processos, participantes envolvidos nesses processos e circunstâncias que informam esses processos. Existem inúmeras ações e atividades, como existem formas variadas de se representá-las linguísticamente. A Gramática Funcional considera, no entanto, que as gramáticas das línguas organizam esses modos diferenciados de representação de ações por meio de um número limitado de processos.

Os principais processos são: os materiais, que englobam os processos de fazer; os mentais, que coordenam os processos de sentir, de ver, de pensar e cuja responsabilidade é expressar o mundo mental; os relacionais, que são os responsáveis pela expressão da noção de estar e de ser; os verbais, que dizem respeito aos processos de dizer e de comunicar e também incluem os verbos de enunciações; os semióticos que, a maioria das vezes, não são verbais; os comportamentais, que se relacionam aos processos fisiológicos do homem; os existenciais que, 
embora se assemelhem aos relacionais no sentido de que constroem sujeitos envolvidos por um processo de ser, distinguem-se destes por envolverem apenas um participante.

Com relação ao sistema de modo, responsável pela expressão linguística da metafunção interpessoal, cabe dizer que é na oração que a Gramática Funcional encontra sua unidade fundamental de análise, pois é nela que o significado expressa-se. Além disso, é também na oração que os eventos interativos entre falante e interlocutor são organizados. Ao falarmos, adotamos um papel discursivo particular e, consequentemente, atribuímos, ao nosso interlocutor, determinado papel complementar o qual esperamos que ele preencha.

O significado interpessoal entre o falante e o seu interlocutor manifesta-se com base em diferentes áreas da linguagem, como a modalidade, a entonação ou os itens lexicais. Dar e pedir são os dois tipos discursivos que categorizam os discursos mais particulares que podemos reconhecer. Assim, podemos dar ou pedir informação ou bens e serviços. Nos pedidos de informações, a oração toma a forma de proposição; nos casos de bens e serviços, a oração toma a forma de uma proposta.

Quanto à metafunção textual, esta se realiza no nível léxico-gramatical do sistema de tematização. Podemos dizer que, de modo geral, o tema pode ser identificado como o primeiro elemento a surgir na mensagem, como resultado da combinação de tema e de rema. É no tema que a mensagem tem o seu ponto de partida. Parte-se do pressuposto de que toda a oração é resultado da escolha do tema.

Muito poderia ser dito ainda sobre os princípios fundadores da Gramática Funcional, mas o que acreditamos ser imprescindível dizer é que essa gramática é, acima de tudo, uma gramática semântica, cujos níveis discursivo-semântico e léxico-gramatical estão particularmente relacionados às relações contextuais e textuais, em termos do modo como os textos se organizam do ponto de vista lexical e gramatical em frases em que as escolhas feitas são extremamente produtivas para o que tencionamos fazer ou dizer.

O modelo da Gramática Funcional, por sua natureza, assenta-se na função social da linguagem e dos seus usos e, por esse ponto de vista, diferencia-se radicalmente do modelo formal, lógico-mentalista, em que o sistema ao ser descrito não considera os falantes naturais em seu contextos culturais e situacionais em condições concretas de uso linguístico, perdendo, por essa razão, inúmeros significados atribuídos aos textos produzidos 


\section{Conclusão}

É essa articulação particularmente feliz entre o social, o contextual, o cultural e o linguístico que torna a Gramática Funcional um modelo sobremaneira produtivo no que toca à compreensão da gramática produzida por falantes reais, dos seus atos, dos seus textos e dos seus processos significativos em uma rede de escolhas hierarquizadas, paradigmáticas, em que as escolhas, mesmo quando inconscientes, são sempre significativas.

Assim, ainda que, para Halliday (1994, p. xvii) um texto seja uma unidade semântica e não uma unidade gramatical, seus significados são realizados por meio de palavras e, sem uma teoria de palavras, ou seja, de uma gramática, não há como fazer uma interpretação explícita do significado do texto. Assim, o interesse atual da ADC, para compreender a gramática, reside no fato de prover um contexto em que a gramática legitimamente desempenha um papel central. Portanto, deve-se, ao término deste artigo, concordar mais uma vez com o que é dito por Halliday, que afirma que uma ADC que não se baseia em uma gramática não é uma análise, mas simplesmente um comentário de um texto.

\section{Referências}

BOLINGER, D. Forms of English. Cambridge, MA: Harvard University Press, 1952.

Intonation and its parts. Stanford, CA: Stanford University Press, 1986.

Intonation and its uses. Stanford, CA: Stanford University Press, 1989.

CUMMING, S; ONO, T. El discurso y la gramática. In: El discurso como estructura y processo. VAN DIJK, T. A. (Comp). Barcelona: Gedisa Editorial, 2000.

DANES, F. Functional sentence perspective and the organization of the text. In: DANES, F. (Comp). Papers on functional sentence perspective. Praga: Academia, 1974, p. 106-28.

FAIRCLOUGH, N. Discourse and social change. Polity Press: Cambridge, UK, 1992.

FIRB AS, J. On defining the theme in functional sentence perspective. Travaux Linguistiques de Prague, 2: 267-80, 1966.

GRIMES, J. The thread of discourse. La Haya: Mouton, 1975.

GREENBERG, J. Language universals. La Haya: Mouton, 1966.

HALLIDAY, M. An introduction to functional grammar. London: Edward Arnold, 1994

. Notes on transitivity and theme in English, parts 1-3. Journal of Linguistics, 3 (1): 37-81, 1967.

HOOPER, P. Emergent grammar and the a-priori grammar postulate. In: D., Tannen (comp). Linguistics in context: connecting, observation, and understanding. Norwood, NJ: Ablex, 1988, p. 117-34,

LONGACRE, R. E. Hierarchy and universality of discourse constituents in New Guinea languages discussion. Washington: Georgetown/ University Press, 1972.

MATHESIUS, V. A functional analysis of present-day english on a general linguistic basis. DUSKOVA, L. (trad); VECEK, J. (comp). Praga: Academia, 1975.

IKE, K. Language in relation to an unified theory of the structure of human behavior. La Haya: Mouton, 1954. 